\title{
Training in Capillaroscopy: A Growing Interest
}
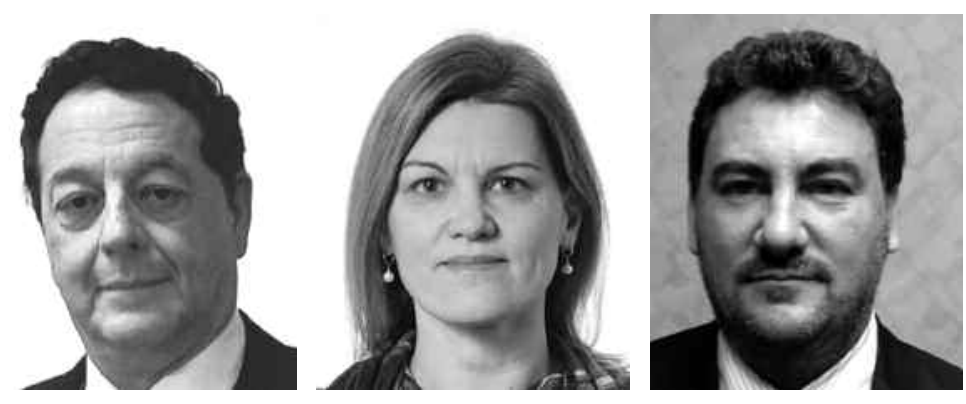

The pilot study by Gutierrez, et al in this issue of The Journal suggests that after a short intensive one-week training program, novice investigators with little or no experience in nailfold videocapillaroscopy (NVC) are able to interpret the main capillary abnormalities in systemic sclerosis (SSc, scleroderma patterns) and to achieve good interreader agreement rates ${ }^{1}$.

This attempt, worthy of encomium, also merits a detailed analysis to show its correct place in the "state of the art" of capillaroscopy with respect to rheumatology and in particular to systemic sclerosis.

\section{STATE OF THE ART}

Although capillaroscopy was born in the 18th Century, when the Italian physician Giovanni Rasori (1766-1837) first noted the close relationship between conjunctival inflammation and the presence of an "inextricable knot of capillary loops" using a "magnifying glass," it was only in 1973 that Maricq and LeRoy published the first article describing the specific capillaroscopic pattern in $\mathrm{SSc}^{2}$.

However, for several decades thereafter capillaroscopy had difficulties to become an accepted and widely used diagnostic technique in SSc. Interestingly, a Medline search performed using the term "capillaroscopy" (retrieving a total of 759 articles from 1973 to today) revealed 22 articles published between 1973 and 1980 (7 years), 548 articles between 1980 and 2008 (28 years), and 189 articles between 2008 and 2011 (only 3 years). Further, among 200 articles that focused on "capillaroscopy and systemic sclerosis" from 1973 up to 2011, almost 80 articles (40\%) were published between 2008 and 2011.

These aspects of its evolution were discussed in a 2009 editorial supporting the growing need for nailfold capillaroscopy in rheumatology and suggesting the main reason for its limited past use: a lack of dissemination of its value in rheumatology circles ${ }^{3}$.

In fact, other reasons may account for the slow growth of the use of capillaroscopy, despite its being recognized from the beginning as the safest, most reliable tool for early diagnosis of SSc (i.e., by using it for the detection of scleroderma patterns).

\section{CAPILLAROSCOPY AND CLASSIFICATION CRITERIA OF SYSTEMIC SCLEROSIS}

An important issue is that for a long time, capillaroscopic findings of the scleroderma pattern were not included in the classification criteria of SSc, and only after 2000 were they introduced in published classification criteria ${ }^{4,5}$. Interestingly, in 2001 the sensitivity of the American College of Rheumatology (ACR) criteria to identify patients with limited disease was found to be significantly improved with addition of nailfold capillary abnormalities and visible telangiectasias (from $34 \%$ to $89 \%)^{6}$.

Recently, 101 patients with SSc were analyzed for the same purpose and, of these, 68 (67\%) met ACR classification criteria ${ }^{7}$. However, the sensitivity increased from $67 \%$ to $99 \%$ with the addition of the nailfold capillary abnormalities identified using a simple dermatoscope and visible telangiectasias.

Further, a 20 -year prospective study ${ }^{8}$ was the first to validate criteria for early diagnosis of $\mathrm{SSc}$, as proposed by LeRoy and Medsger in The Journal ${ }^{9}$, in which capillaroscopy was considered as an essential diagnostic tool. The study also confirmed the value of capillaroscopy to predict progression to definite SSc in patients with Raynaud's phenomenon (RP) with scleroderma- and/or SSc-specific antibodies.

More recently, after 3 Delphi rounds seeking expert opinion criteria for very early SSc and categorizing of their 121 items into 3 domains containing 7 items, it was suggested that abnormal capillaroscopy with scleroderma pattern showed the highest sensitivity and specificity together with RP and specific autoantibodies ${ }^{10}$. Clearly, all these investigations over the last decade have increased the inter-

See Learning curve in videocapillaroscopy, page 1248

Personal non-commercial use only. The Journal of Rheumatology Copyright @ 2012 . All rights reserved. 
est and need for capillaroscopy, at least in the early diagnosis of SSc.

\section{PATTERNS AND CAPILLAROSCOPY}

Indeed, further strong support for the broader use of capillaroscopy arose from the recent validated description, definition, and scoring of the different scleroderma patterns using nailfold videocapillaroscopy $(\mathrm{NVC})^{11,12,13}$. The presence of giant capillaries and microhemorrhages on NVC is now validated as sufficient to identify the early scleroderma pattern (early), whereas an increase in these features in addition to loss of capillaries identify the active pattern (active scleroderma pattern) and is followed by neoangiogenesis, fibrosis, and "desertification" (late scleroderma pattern; Figure 1). These patterns were described for the first time in The Journal ${ }^{14}$. Based on the appearance of the early NVC scleroderma pattern, almost $15 \%$ of patients move from primary to secondary RP over a mean followup period of 29.4 \pm 10 months

Recently, a 7-year longitudinal study involving patients with SSc with the early scleroderma NVC pattern demonstrated a dynamic transition of microvascular damage through the different NVC patterns of microangiopathy in almost $50 \%$ of patients ${ }^{15}$. In particular, the active scleroderma pattern was seen in $34 \%$, the late scleroderma pattern in $13 \%$, and a normal pattern in $5 \%$. The mean time of pro- gression from the early to the active pattern and from the early to the late pattern was $28 \pm$ SD 20 months and $36 \pm$ SD 29 months, respectively. Interestingly, clinical symptoms progressed in accordance with the nailfold morphologic changes in $60 \%$ of the patients with SSc.

\section{EDUCATION AND TRAINING IN CAPILLAROSCOPY}

Of course, these clinical achievements linking the NVC to SSc progression and management have increased the need for efficient education and training for rheumatologists at least to learn the correct use of capillaroscopy. To date, capillaroscopy full-immersion training courses (held in Italy in 2004, 2006, 2008, 2010, and planned for September 2012) have recently been provided by international faculties and supported by the European League Against Rheumatism (EULAR). In addition, from 2010, a study group dedicated to "capillaroscopy and rheumatic diseases" was started at the ACR.

Recently, it was demonstrated that technical skill in NVC can quickly be attained by a short period of training; moreover, to implement learning and training in NVC in the rheumatic diseases an atlas/textbook has been published under the aegis of EULAR and the authorship of the most prominent world experts ${ }^{16,17}$.

In a recent survey listing 14 tools for the diagnosis of

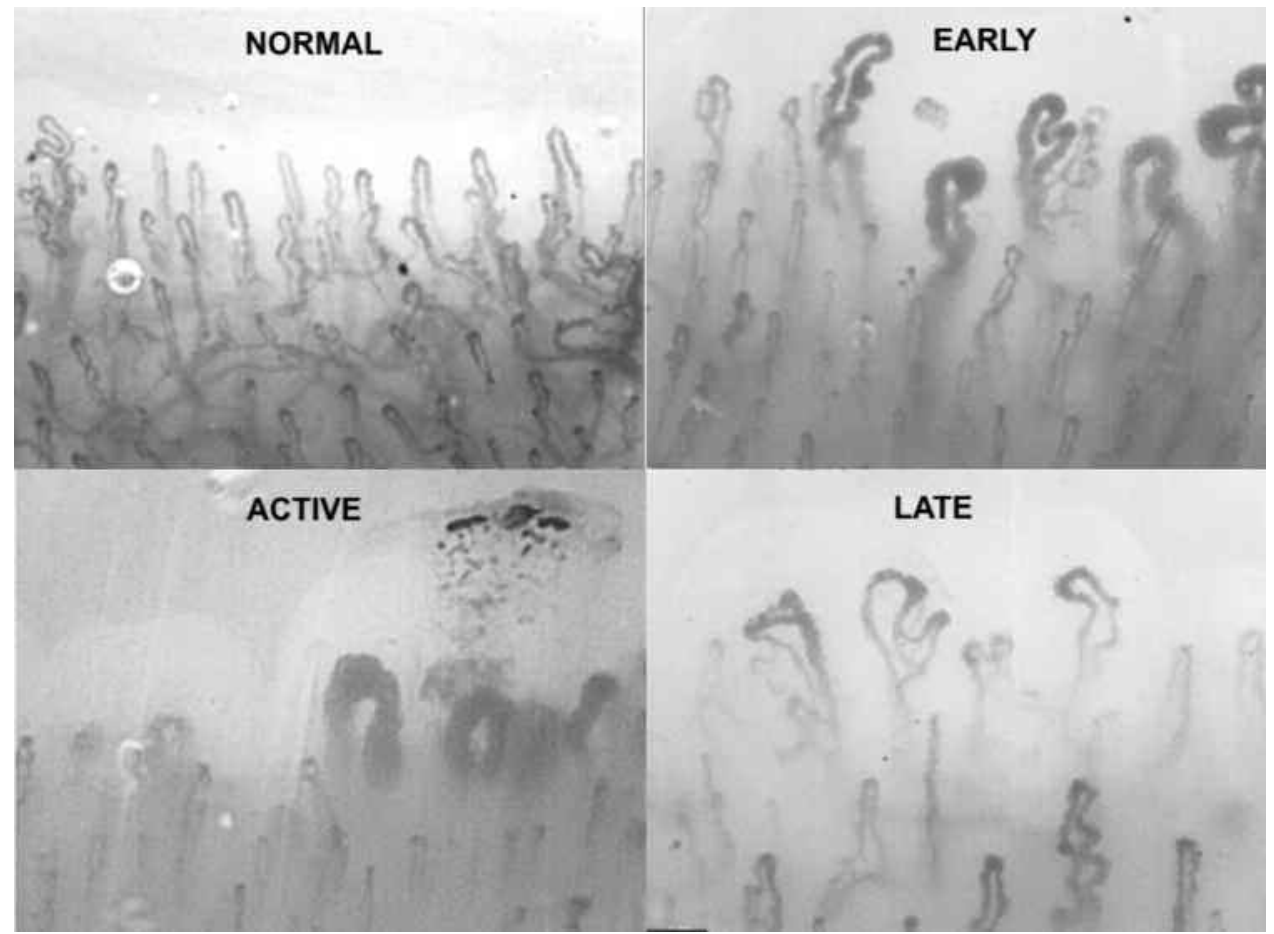

Figure 1. Nailfold bed capillary array analyzed by nailfold videocapillaroscopy (NVC). The presence of giant capillaries and microhemorrhages identifies the early NVC scleroderma pattern (Early); an increase in these features and the addition of loss of capillaries identify the active pattern (Active); and the presence of angiogenesis, fibrosis, and massive loss of normal capillaries characterizes the late NVC pattern (Late). The normal pattern does not show any of these capillary alterations (original magnification 200x). 
rheumatic diseases, participants, who were 170 young rheumatologists (113 trainees and 57 specialists, $33 \pm 4.2$ years of age) from 32 EULAR countries, considered capillaroscopy as the second most interesting tool for their future learning ${ }^{18}$. In particular, although actual knowledge of capillaroscopy was admitted in only $6.4 \%$ of those interviewed compared to $50 \%$ in ultrasound, for example, interest for further learning was $31 \%$ and $68.2 \%$ of participants, respectively, placing both tools at a superior level of interest, with capillaroscopy at the top, compared with all the other 14 tools ${ }^{18}$

Indeed, the requirement in demonstrating competence in interpreting NVC abnormalities is now part of the "core curriculum" for rheumatologists in Europe.

In light of these growing facilities and opportunities to optimize "materials and methods" for the use of capillaroscopy, at least in SSc, the impressive growth of published studies in very recent years is a pleasant and expected consequence.

In particular, the recent study by Gutierrez, et $a l^{1}$ providing evidence of a learning curve in interpreting nailfold capillary abnormalities and scleroderma pattern by NVC for inexperienced readers and achieving a good interreader agreement after one week of intensive training is a further important contribution.

Interestingly, in this educational program inexperienced readers were not able to discern the "normal" NVC pattern from the scleroderma patterns, suggesting that future programs will need to focus better on distinctions between normal and scleroderma patterns.

Notably, the issue of "normal" has always represented an enigma in medicine; however, in capillaroscopy the normal capillaroscopic pattern is simply a picture that does not show the major markers of disease and that qualifies the scleroderma patterns (namely, giant capillaries and related microhemorrhages, loss of capillaries, and angiogenesis). There exists also a series of morphological microvascular variations/abnormalities that represent an overlap between the range of normality and/or related to sequellae of local trauma. These abnormalities include mainly tortuosity, capillary crossing, bizarre capillaries, ectasias, skin transparen$\mathrm{cy}$, and visibility of the subpapillary venous plexus, and localized posttraumatic microhemorrhages.

\section{CLINICAL USE OF CAPILLAROSCOPY}

Lastly, it seems that the most attractive reason for broaderbased learning and use of NVC is the assessed predictive value for progression of clinical complications of SSc, linked to the different NVC scleroderma patterns and including the scoring of severity.

Nailfold capillary density, for example, is associated with the presence and severity of pulmonary arterial hypertension in SSc or with progression of digital ulcers ${ }^{19,20,21}$.

In addition, by a more widespread employment of capil- laroscopy, it should be possible to identify patients with $\mathrm{SSc}$, for example, at different levels of severity of digital vascular disease, for recruitment into clinical trials in which capillaroscopy will be one of several or even the major outcome measure.

The right time for broader use of capillaroscopy is now: this is obvious because of the current availability of different drugs to test in clinical trials in SSc, the increased international networking of clinicians with an interest in RP, and the validation of the diagnostic value of $\mathrm{NVC}^{22}$.

In conclusion, capillaroscopy, particularly $\mathrm{NVC}$, is a safe, noninvasive, and reliable tool that has recently gained an important role in early diagnosis, prediction of disease progression, and management of SSc. Further progression and optimization of the potentialities of nailfold videocapillaroscopy is linked to widespread training and education on its use.

\section{MAURIZIO CUTOLO, MD,}

Research Laboratory and Academic Unit of Clinical Rheumatology, Department of Internal Medicine,

University of Genova,

Genova, Italy;

VANESSA SMITH, MD, $\mathrm{PhD}$,

Department of Rheumatology,

Ghent University Hospital,

Ghent, Belgium;

\section{ALBERTO SULLI, $\mathrm{MD}$,}

Research Laboratory and Academic Unit of Clinical Rheumatology, Department of Internal Medicine,

University of Genova,

Genova, Italy

Address correspondence to Prof. M. Cutolo, Department of Internal Medicine, University of Genova, Viale Benedetto XV, 6, 16132 Genova, Italy.E-mail: email: mcutolo@unige.it

\section{REFERENCES}

1. Gutierrez M, Bertolazzi C, Tardella M, Becciolini A, Di Carlo M, Dottori $\mathrm{M}$, et al. Interreader reliability in assessment of nailfold capillary abnormalities by beginners: Pilot study of an intensive videocapillaroscopy training program. J Rheumatol 2012;39:1248-55.

2. Maricq HR, LeRoy EC. Patterns of finger capillary abnormalities in connective tissue disease by "wide-field" microscopy. Arthritis Rheum 1973;16:619-28.

3. De Angelis R, Grassi W, Cutolo M. A growing need for capillaroscopy in rheumatology. Arthritis Rheum 2009;61:405-10.

4. Maricq HR, Valter I. A working classification of scleroderma spectrum disorders: A proposal and the results of testing on a sample of patients. Clin Exp Rheumatol 2004;22 Suppl 33:S5-13.

5. Cutolo M, Matucci Cerinic M. Nailfold capillaroscopy and classification criteria for systemic sclerosis. Clin Exp Rheumatol 2007;25:663-5.

6. Lonzetti LS, Joyal F, Raynauld JP, Roussin A, Goulet JR, Rich E, et al. Updating the American College of Rheumatology preliminary classification criteria for systemic sclerosis: Addition of severe nailfold capillaroscopy abnormalities markedly increases the sensitivity for limited scleroderma [letter]. Arthritis Rheum 2001;44:735-6.

7. Hudson M, Taillefer S, Steele R, Dunne J, Johnson SR, Jones N, et al. Improving the sensitivity of the American College of 
Rheumatology classification criteria for systemic sclerosis. Clin Exp Rheumatol 2007;25:754-7.

8. Koenig M, Joyal F, Fritzler MJ, Roussin A, Abrahamowicz M, Boire $\mathrm{G}$, et al. Autoantibodies and microvascular damage are independent predictive factors for the progression of Raynaud's phenomenon to systemic sclerosis: A twenty-year prospective study of 586 patients, with validation of proposed criteria for early systemic sclerosis. Arthritis Rheum 2008;58:3902-12.

9. LeRoy EC, Medsger TA Jr. Criteria for the classification of early systemic sclerosis. J Rheumatol 2001;28:1573-6.

10. Avouac J, Fransen J, Walker UA, Riccieri V, Smith V, Muller C, et al. EUSTAR Group. Preliminary criteria for the very early diagnosis of systemic sclerosis: Results of a Delphi Consensus Study from EULAR Scleroderma Trials and Research Group. Ann Rheum Dis 2011;70:476-81.

11. Smith V, Pizzorni C, De Keyser F, Decuman S, Van Praet JT, Deschepper E, et al. Reliability of the qualitative and semiquantitative nailfold videocapillaroscopy assessment in a systemic sclerosis cohort: A two-centre study. Ann Rheum Dis 2010;69:1092-6.

12. Hofstee HM, Serné EH, Roberts C, Hesselstrand R, Scheja A, Moore TL, et al. A multicentre study on the reliability of qualitative and quantitative nail-fold videocapillaroscopy assessment. Rheumatology 2011 Dec 20. [Epub ahead of print]

13. Sulli A, Secchi ME, Pizzorni C, Cutolo M. Scoring the nailfold microvascular changes during the capillaroscopic analysis in systemic sclerosis patients. Ann Rheum Dis 2008;67:885-7.

14. Cutolo M, Sulli A, Pizzorni C, Accardo S. Nailfold videocapillaroscopy assessment of microvascular damage in systemic sclerosis. J Rheumatol 2000;27:155-60.

15. Sulli A, Pizzorni C, Smith V, Zampogna G, Ravera F, Cutolo M. Timing of transition between capillaroscopic patterns in systemic sclerosis. Arthritis Rheum 2012;64:821-5.
16. De Angelis R, Cutolo M, Salaffi F, Restrepo JP, Grassi W. Quantitative and qualitative assessment of one rheumatology trainee's experience with a self-teaching programme in videocapillaroscopy. Clin Exp Rheumatol 2009;27:651-3.

17. Smith V, Cutolo M. When and how to perform capillaroscopy. In: Cutolo M, editor. Atlas of capillaroscopy in rheumatic diseases. Milan: Elsevier; 2010:33-42.

18. Bandinelli F, Bijlsma JW, Ramiro MS, Pia E, Goekoop-Ruiterman YP, Sivera F, et al. Rheumatology education in Europe: Results of a survey of young rheumatologists. Clin Exp Rheumatol 2011;29:843-5.

19. Hofstee HM, Vonk Noordegraaf A, Voskuyl AE, Dijkmans BA, Postmus PE, Smulders YM, et al. Nailfold capillary density is associated with the presence and severity of pulmonary arterial hypertension in systemic sclerosis. Ann Rheum Dis 2009;68:191-5.

20. Smith V, De Keyser F, Pizzorni C, Van Praet JT, Decuman S, Sulli A, et al. Nailfold capillaroscopy for day-to-day clinical use: Construction of a simple scoring modality as a clinical prognostic index for digital trophic lesions. Ann Rheum Dis 2011;70:180-3.

21. Ingegnoli F, Boracchi P, Gualtierotti R, Biganzoli EM, Zeni S, Lubatti C, et al. Improving outcome prediction of systemic sclerosis from isolated Raynaud's phenomenon: Role of autoantibodies and nail-fold capillaroscopy. Rheumatology 2010;49:797-805.

22. Herrick AL, Cutolo M. Clinical implications from capillaroscopic analysis in patients with Raynaud's phenomenon and systemic sclerosis. Arthritis Rheum 2010;62:2595-604.

J Rheumatol 2012;39:1113-16; doi:10.3899/jrheum.120082 